\title{
Conjugated linoleic acid feeding during rat suckling period enhances intestinal IgA production
}

\author{
F. J. Pérez-Cano, M. Molero, C. Ramírez-Santana, M. Castell, C. Castellote and A. Franch \\ Department of Physiology, Faculty of Pharmacy, University of Barcelona, Barcelona, Spain
}

Conjugated linoleic acid (CLA) is a mixture of isomers of linoleic acid, of which cis-9, trans-11 and trans-10, cis-12 are the major constituents. These compounds induce beneficial effects on health and it has been suggested that they may modulate immune responses. However, as in man, mucosal Ig production is poorly developed during the suckling period in rats. The aim of the present work was to establish the effect of CLA on mucosal immunity during suckling by determining IgA levels in intestinal washes from 28 -d-old Wistar rats by an ELISA technique. IgA and PPAR- $\gamma$ (as a possible mediator of the CLA effect) mRNA expression in small intestine and colon from 21- and 28-d-old Wistar rats was also evaluated by real-time PCR. Pregnant Wistar rats were obtained on day 7 of gestation. On the day of birth pups were divided into eight different groups. Four groups were analysed on day 21: litters from mothers fed with CLA (80\% cis-9, trans-11, $20 \%$ trans-10, cis-12; Lipid Nutrition B. V. Wormerveer, The Netherlands $; 10 \mathrm{~g} / \mathrm{kg}$ pellet chow) during gestation and lactation (A); CLA only during gestation but litters received a CLA isomer mixture by daily oral supplementation during suckling (B); exclusively receiving CLA by oral administration during the suckling period $(\mathrm{C})$; a parallel-age reference group. Another four groups were studied at $28 \mathrm{~d}$ old: litters receiving CLA from day 1 to 28 (D); from day 1 to 21 (X); from weaning to day 28 (E); a parallel-age reference group (Z). On days 21 and 28 rats were killed and samples from the small intestine and colon were removed for RNA extraction for later real-time PCR. Taqman ${ }^{\circledR}$ specific probes and primers were used for each gene (Applied Biosystems, Foster City, CA, USA). Target gene expression was normalised by GADH and $\beta$-actin endogenous controls in each sample. In all cases statistical analysis was performed by conventional ANOVA, and when the experimental group variable had a significant effect on the dependent variable post hoc comparisons (LSD test) were performed. Differences were considered to be significant at $P<0.05$. The results provided evidence that mucosal production of IgA increased in animals supplemented with CLA during suckling by increasing IgA mRNA expression in the small intestine and colon and IgA protein in 28-d-old rats (see Table). PPAR $\gamma$ gene expression was also up regulated in animals receiving CLA during early life. In conclusion, dietary supplementation with CLA during suckling enhances the development of the immune system in Wistar rats. Moreover, the effect of CLA supplementation is better when supplementation is given earlier and for longer.

\begin{tabular}{|c|c|c|c|c|c|}
\hline \multirow[b]{3}{*}{ Age } & \multirow[b]{3}{*}{ Group } & \multicolumn{4}{|c|}{ IgA expression $(\%)$ (normalized by $\beta$-actin) } \\
\hline & & \multicolumn{2}{|c|}{ Small intestine } & \multicolumn{2}{|c|}{ Colon } \\
\hline & & Mean & SE & Mean & $\mathrm{SE}$ \\
\hline \multirow[t]{4}{*}{ Day 21} & A & 149.1 & 28.15 & 136.1 & 52.94 \\
\hline & B & 73.81 & 29.32 & 114.9 & 29.19 \\
\hline & $\mathrm{C}$ & 179.6 & 80.69 & 206.6 & 62.10 \\
\hline & $\mathrm{W}$ & 100.0 & 39.27 & 100.0 & 20.25 \\
\hline \multirow[t]{4}{*}{ Day 28} & $\mathrm{D}$ & $545.8^{*}$ & 190.4 & $372.5 *$ & 122.2 \\
\hline & $\mathrm{X}$ & 15.91 & 5.04 & 40.32 & 10.82 \\
\hline & $\mathrm{E}$ & 49.85 & 23.22 & 79.30 & 15.75 \\
\hline & $\mathrm{Z}$ & 100.1 & 19.53 & 99.85 & 28.24 \\
\hline
\end{tabular}

Mean values were significantly different from those for groups $\mathrm{E}, \mathrm{X}$ and $\mathrm{Z}(n 4-5)$ : $* P<0.05$. 